\title{
Effect of sugarcane bagasse fibre on the flexural behavior of geopolymer concrete RCC beams
}

\author{
Srimanthula Chandana ${ }^{l}$, T.Srinivas ${ }^{2}$ and $N V$ Ramana Rao $^{3}$ \\ ${ }^{1}$ PG Student, Department of Civil Engineering, GRIET, Hyderabad -500085 \\ ${ }^{2}$ Professor, Department of Civil Engineering, GRIET, Hyderabad -500085 \\ ${ }^{3}$ Professor, Department of Civil Engineering, JNTU, Hyderabad -500085
}

\begin{abstract}
CO} 2$ is released into the atmosphere during the manufacture of Ordinary Portland Cement (OPC). Fly ash, a by-product of the coal industry, is used to replace OPC in concrete. It contains a lot of silicate gel and is mixed with an alkaline solution to make good concrete. Increased fly ash fineness improves compressive strength while lowering porosity. Advances in modern bio technology is possible freedoms for monetary use of agro-mechanical deposits like sugarcane bagasse ash and fibre. The flexural behaviour of Geopolymer Concrete RCC beams with and without sugarcane bagasse fibre, i.e. GPC and GPCF of G 40 grade, equal to M40, is presented in this study. The $150 * 150 \mathrm{~mm}$ beam is cast across a 1,200 $\mathrm{mm}$ effective span and tested for failure under static loads. The ultimate load and load displacement responses of GPC structural elements with and without fibre are measured and compared to normal GPC and conventional concrete elements. The findings suggest that SCBF improves the flexural strength, service load, and peak load of GPC elements.
\end{abstract}

\section{Introduction}

In current time, fibre composites are acquiring consideration because of its predominant benefits like high explicit strength and modulus, financial reasonability, less thickness, biodegradability, climate well disposed, minimal expense, diminished device wear, improved energy recuperation, decreased dermal and respiratory disturbance over customary metallic combinations. The attention in regular fibre-supported composite of polymer materials is quickly expanding in both modern applications and crucial exploration. The likely utilization of regular filaments are discovered appealing in non-industrial nations, where they are frequently accessible in tropical plants and agrarian squanders* that right now have restricted monetary worth. Persistent advancement in the creation of normal fibre composites has for the most part cantered around mechanical improvement and decrease of primary deformities to guarantee toughness, unwavering quality, cost decrease and expanded creation rates. Climate cordial materials are advanced .Normal filaments are inexhaustible, modest, biodegradable and totally or to some degree recyclable. Due to their acceptable mechanical qualities and accessibility, plants such as knead, jute, flax, hemp, sisal, cotton, pineapple, ramie, bamboo, banana, and others are believed to be regular strands, ecoinvitingness, sustainability, cost and low thickness and a solid option to the artificial fibre parts like glass, carbon utilized in the manufacture of polymer

\footnotetext{
${ }^{* *}$ Corresponding author : srinu.tummala@gmail.com
}

framework composites. The effects of water retention on the mechanical characteristics of hemp fibre-based unsaturated polyester-based regular composites have been studied in Dhaka. The outcomes show that the dampness get increments with the fibre volume part. An increment in dampness get decreases the flexural and malleable properties by polymer debasement. Grande explored the fibre content and width impactson the Leukaemia sort fibre supported polypropylene regular composite. It was discovered that increasing the fibre percentage from $20 \%$ to $50 \%$ increased the composite's solidity. The firmness qualities are unaffected by the fibre breadth. Osman et al. [11] investigated the sway and flexural properties of sisal, banana, jute, and flax regular fibre built up polypropylene framework composites. They discovered that sisal fibre is superior to other filaments.

Improving the flexural and effect properties of the composites, and ensuring that these qualities are unaffected by the fibre content, using the expulsion and infusion shaping cycle to create a durian skin fibre supported normal composite. The durian filaments utilised in this study were either untreated or pretreated with $\mathrm{NaOH}$. They discovered that pre-treated filaments significantly improve the mechanical properties of regular composites and provide superior warm solidity when compared to untreated regular composites. They likewise proposed that the surface medicines of regular filaments are fundamental to further develop the holding attributes by eliminating the soil, dampness from the fibre and expanding the surface harshness of the fibre. 


\subsection{Methodology}

Sugarcane bagasse was collected and submerged in a $\mathrm{NaOH}$ solution for one day to alkalize it. After that, the bagasse was let to dry naturally in the open field for several days. A universal power blender was used to crush the sugarcane bagasses. The needle-like filaments were discovered after being dried and crushed. The fibres are then dried a second time in an oven at $50^{\circ} \mathrm{c}$.

When bagasse fibre with varied volume fractions was studied by Isiaka Oluwole Oladele $(5,10,15$ and 20 percent ). The samples were subjected to mechanical testing. And it was discovered that a $10 \mathrm{wt} \%$ bagasse fibre loading offered good results in many tests, and that bagasse particulate fibre in the range of $5-10 \mathrm{wt} \%$ gave the best results compared to other volume fractions (15 to $20 \mathrm{w}$ percent ). The characteristics and chemical makeup of bagasse fibres are the focus of this review. It is a challenge to develop better materials with improved mechanical properties in order to improve quality of life. Bagasse fibres' physical qualities, mechanical properties, fibre kinds, and chemical makeup are also discussed in this review. This research is to take advantage of the advantages that renewable resources provide for the creation of bagasse-based composite materials. It is a challenge to develop better materials with improved mechanical properties in order to improve quality of life. The use of bagasse fibre is also discussed in this review.

\subsection{Material}

\begin{tabular}{|c|c|}
\hline Grade of concrete & Mix \\
\hline FlyAsh & 327.25 \\
\hline GGBS $\left(\mathrm{kg} / \mathrm{m}^{3}\right)$ & 57.75 \\
\hline Fine Aggregate $\left(\mathrm{kg} / \mathrm{m}^{3}\right)$ & 684 \\
\hline $\begin{array}{c}\text { Coarse Aggregate } \\
\left(\mathrm{kg} / \mathrm{m}^{3}\right)\end{array}$ & 1198.114 \\
\hline $\begin{array}{c}\text { Super plasticizer } \\
\text { Noah }\left(\mathrm{kg} / \mathrm{m}^{3}\right) 12 \mathrm{M}\end{array}$ & $2 \%$ \\
\hline $\begin{array}{c}\text { Na } 2 \text { SiO } \\
\text { ( }\left(\mathrm{kg} / \mathrm{m}^{3}\right)\end{array}$ & 110 \\
\hline $\begin{array}{c}\text { Ratio of mix } \\
\text { proportions }\end{array}$ & $1: 1.786: 3.128$ \\
\hline W/C ratio & \\
\hline Water content & 28.174 \\
\hline Workability & $75-100 \mathrm{~mm}$ \\
\hline
\end{tabular}

1. IS 12269-1987 Ordinary Portland Cement (53 grade)

2.IS 3812 (Part 1) :2003 2. Fly ash (class F)

3. IS 12089:1987 Ground Granulated Blast Furnace

Slag (GGBS)

4. IS: $383-1970$ coarse aggregate $(20 \mathrm{~mm})$

5. Alkaline solution: sodium hydroxide $(\mathrm{NaOH})$ pellets (purity 98\%), sodium silicate solution (Na2SiO3)

6. SNF (super plasticizer) (sulphonated Naphthalene formaldehyde)

7. Water

8. Bagasse Fibre from Sugar Cane

\section{Materials and Mix Design}

\subsection{Mix design}

\begin{tabular}{|c|c|}
\hline \multicolumn{2}{|c|}{ M40 grade of concrete } \\
\hline Cement $\left(\mathrm{kg} / \mathrm{m}^{3}\right)$ & 386 \\
\hline Fine Aggregate $\left(\mathrm{kg} / \mathrm{m}^{3}\right)$ & 684 \\
\hline CA $\left(\mathrm{kg} / \mathrm{m}^{3}\right)$ & 1198.114 \\
\hline SP & $1.5 \%$ \\
\hline Mix Proportions Ratio & $1: 1.77: 3.10$ \\
\hline W/C ratio & 0.40 \\
\hline $\begin{array}{c}\text { Workability in terms of Slump } \\
(\mathrm{mm})\end{array}$ & $75-100 \mathrm{~mm}$ \\
\hline
\end{tabular}

Table1: Mix proportions Concrolled concrete (CC)

Table2: Mix proportions Geopolymer concrete (GPC)

This paper was made with a grade M40. For computing the mix plan of M40 and G40 concrete, the system is based on IS:10262-2009 and IS:456-2000. Using the advantages of M40, the G40 for Geopolymer concrete is determined through experimentation. In the experimental on concrete, the last mix of M40 with a W/C ratio of 0.4 is replaced by 85 percent fly ash and 15 percent GGBS. Sugar cane baggase was added about $2 \%$ which both GPC and controlled cement was made fiber and contrasted and ordinary cement.

\section{Specimen and Test setup}

According to investigation research, RCC beams estimating $150 * 150 * 1200 \mathrm{~mm}$ were utilized. Beams protections are point by point in consistence with IS 456-2000 rules, as displayed in Fig.1. 12 mm bars are used as main reinforcement and $8 \mathrm{~mm}$ is used as stirrups. The proper amount of Fly ash, GGBS, fine and coarse aggregate are used to make RCC elements by using M40 and G40 concrete. The mix is consolidated to get required usefulness and afterward to be poured in example with support made for giving examples a role as displayed in Fig 1. Following 24 hours, the entirety of the examples were demoulded as display get required usefulness and afterward to be 
poured in example with support made for giving examples a role as displayed in Fig 1. The full set of instances was demoulded after 24 hours, as seen in Fig 2. GPC test examples were restored for 28 days in states of comprehensive alleviating. It's worth noting that water isn't required for curing.

\section{Test Procedure}

For beams testing, a hydraulic loading frame with a capacity of 200 tonnes is used. For diversions in the range of $10 \mathrm{~mm}$, linear variable differential transducers (LVDT) with a minimum tally of $0.01 \mathrm{~mm}$ are used. To obtain strain in the example, strain check sensors are added to the example. LVDTs, strain gauge sensors, and burden shells are connected to the Signal conditioner/marker via pre-programmed No ports in the charge unit. With a proper stacking rate increment the heap bit by bit till example twists/breaks. The robotized information procurement framework is utilized to dissect the information during the experiment.Observe the break designs on the example and get the information gained from the framework to additionally come to results and end results.

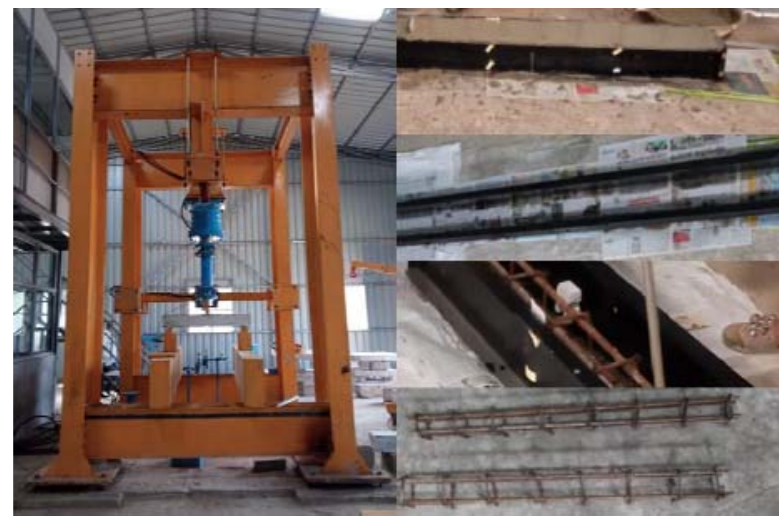

Figure 1. RCC Beam Setup for Testing

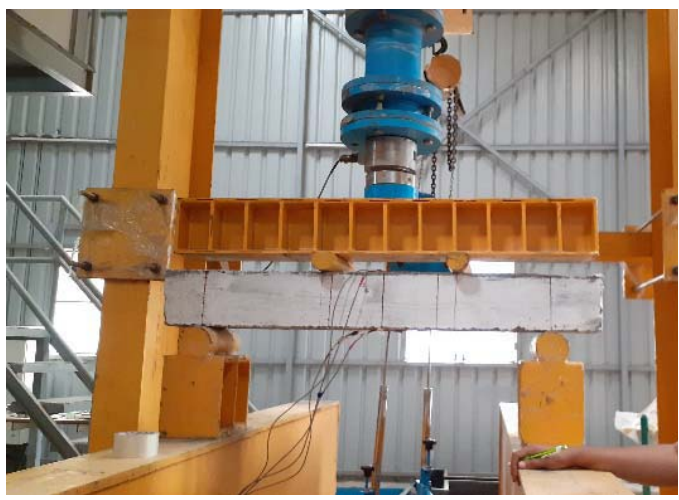

Figure 2. RCC Beam before Testing

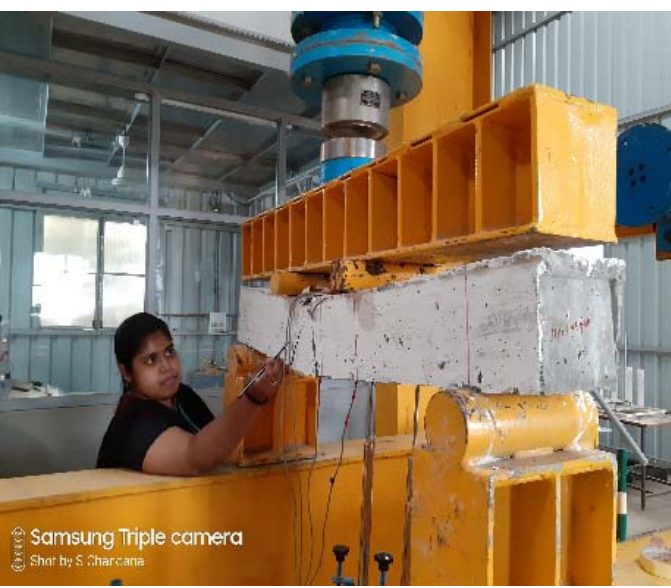

Figure 3. RCC Beam after Testing

\section{Result and Discussion}

Beams were casted about estimating $150 * 150 * 1200$ $\mathrm{mm}$.

Table 1: Loads of Structural Elements

\begin{tabular}{|c|c|c|}
\hline \multicolumn{3}{|c|}{ Beams } \\
\hline S.no & Service load(kn) & Ultimate load(kn) \\
\hline CC & 38.5 & 45.8 \\
\hline GPC & 40.6 & 50.6 \\
\hline CCF & 41.9 & 51.3 \\
\hline GPCF & 46.7 & 58.7 \\
\hline
\end{tabular}

The values are obtained after the testing from $1^{\text {st }}$ crack as service load.thestruvctral elements give higher results at GPCF. The ultimate load has the 58.7, gained at the fibre content of sugarcane bagasse .

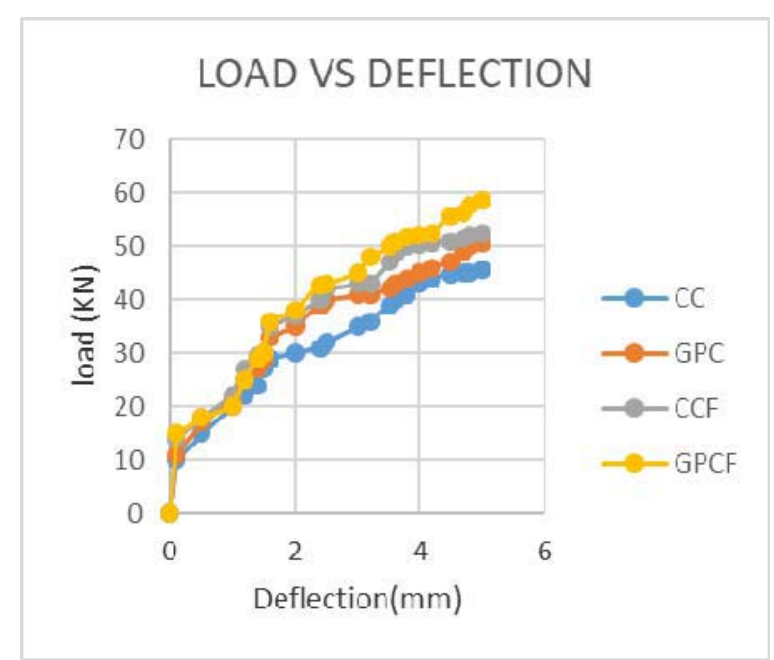


Table 2: Loads againist Deflection (mm) of RCC Beams

\begin{tabular}{|c|c|c|c|c|}
\hline $\begin{array}{c}\text { Deflection } \\
(\mathbf{m m})\end{array}$ & \multicolumn{4}{|c|}{ Load (KN) } \\
\hline & CC & GPC & CCF & GPCF \\
\hline 0 & 0 & 0 & 0 & 0 \\
\hline 0.1 & 10 & 11 & 14 & 15 \\
\hline 0.5 & 15 & 17 & 18 & 18 \\
\hline 1 & 20 & 21 & 22 & 20 \\
\hline 1.2 & 22 & 25 & 27 & 25 \\
\hline 1.4 & 24 & 27 & 29.5 & 29 \\
\hline 1.5 & 27 & 29 & 30 & 30 \\
\hline 1.6 & 29 & 33 & 35 & 36 \\
\hline 2 & 30 & 35 & 37 & 38 \\
\hline 2.4 & 31 & 39 & 40 & 42.8 \\
\hline 2.5 & 32 & 40 & 42 & 43 \\
\hline 3 & 35 & 40.9 & 42.9 & 45 \\
\hline 3.2 & 36 & 41 & 43 & 48 \\
\hline 3.5 & 39 & 42 & 47 & 50 \\
\hline 3.6 & 40 & 43 & 49 & 51 \\
\hline 3.8 & 41 & 44 & 50 & 51.8 \\
\hline 4 & 43 & 45 & 50.5 & 52 \\
\hline 4.2 & 44 & 46 & 50.8 & 52.5 \\
\hline 4.5 & 44.9 & 47 & 51 & 55.8 \\
\hline 4.7 & 45 & 49 & 51.5 & 56.4 \\
\hline 4.8 & 45.2 & 50 & 52 & 57.6 \\
\hline 5 & 45.8 & 50.6 & 52.5 & 58.7 \\
\hline & & & & \\
\hline
\end{tabular}

\section{Conclusion}

1. Load carrying capacity of RCC beam with CCF is found to be $12.01 \%$ more than $\mathrm{CC}$ beam and GPCF is increased by $16.01 \%$ compared to GPC beam.

2. It has been observed that the compressive strength is increased up to $0.5 \%$ of fibre and further increase in dosage of SCBF, compressive strength is fallen.

3. In comparison to CCF and GPCF, CC and GPC showed larger cracks..

4. Workability is decreased as the dosage of SCBF increased, but still it is in the required limit.

5. When compared to $\mathrm{CC}$ beams, the load carrying capacity of GPCF at first crack increased by 21.29 percent and with GPC 15.02 percent rspectively.

6. Deflections are controlled in GPCF and GPC compared to GPC and CC beams.

\section{Reference}

1. M. Ratna srinivas, Y. Himath Kumar, B. Sarath Chandra Kumar , (IJRTE) ISSN: 2277-3878, Volume-7, Issue-6C2, April (2019).

2. M F Nuruddin, A B Malkawil, A Fauzi1, B S Mohammed, H M Almattarneh, IOP Conf. Series: Mat.S.E 133 (2016) 012021.
3. T. Srinivas, P. Manoj Anand, IJITEE, (2019).

4. Ankur Laxman Yadav, V. Sairam, K. Srinivasan, L. Muruganandam, C\&B 258, 119231 (2020).

5. S Kumaravel, $\mathrm{S}$ Thirugnanasambandam and $\mathrm{C}$ Antony, The IUP Journal of Structural Engineering, Vol. VII, No. 1,(2014)

6. .P.Bhavana and Dr.T.Srinivas ,(IJRTE) ISSN: 2277-3878, Dec(2020).

7. Gaurav Nagalia Yeonho Park, M.ASCE, Ali Abolmaali, M.ASCE, and Pranesh Aswath, J. Mater. Civ. Eng., (2016)

8. Karthik Rao, R., Bobba, P.B., Suresh Kumar, T., Kosaraju, S. Materials Today: Proceedings, 26, pp. 3085-3089, 2019

9. Arslan Akbar, Furqan Farooq, Muhammad Shafique, Fahid Aslam, Rayed Alyousef, Hisham AbdulJabbar, Journal of Building Engineering, (2021)

10. T.Srinivas and M. Abinay Raj, Int. J. of Eng.and Adv. Tech. (IJEAT), ISSN: 2249 - 8958, Volume8 Issue-6 (2019)

11. S. Seshadri, M. Kavitha and P. B. Bobba, 2018 International Conference on Power, Instrumentation, Control and Computing (PICC), 2018, pp. 1-6

12. T.srinivas and P. Manoj Anand, Int. J. of Innov. Tech. and Explor. Eng.g (IJITEE), ISSN: 22783075, Volume-8 Issue-12 (2019)

13. T.Srinivas and G. Sukesh Reddy, Int. J. of Eng.and Adv. Tech. (IJEAT), ISSN: 2249 - 8958, Volume9 Issue-1 (2019)

14. B. T. P. Singh, B. P. Babu and Y. Satyavani, 2019 IEEE Transportation Electrification Conference (ITEC-India), 2019, pp. 1-6

15. T.Srinivas and R. N. Koushik, Int. J. of Innov. Tech. and Explor. Eng.g (IJITEE), ISSN: 22783075, Volume-8 Issue-12 (2019), PP 112-117.

16. K. Sai Gopi, Dr. T. Srinivas and S. P. Raju V, E3S Web of Conferences ICMED 184, 01084GRIET, 28-29

February, https://doi.org/10.1051/e3sconf/2020184011084(2 020)

17. Jagannadha Kumar, M.V., Jagannadha Rao, K., Dean Kumar, B., Srinivasa Reddy, V., Int. J. of Civil Eng. and Tech., 9(7), pp. 1133-1141 (2018)

18. K. satyanarayana, S. K. Singh, T. Buddi, K. Anil and A. Ul Haq, Advances in Materials and Processing Technologies, 6(2), 365 (2020)

19. Ganta, J.K., Seshagiri Rao, M.V., Mousavi, S.S., Srinivasa Reddy, V., Bhojaraju, C., Structures 28, pp. 956-972 (2020)

20. Naidu, K.S.S.T., Rao, M.V.S., Reddy, V.S., Int. J. of Innov. Tech. and Explor. Eng.g (IJITEE), 8(9 Special Issue 2), pp. 641-642 (2019)

21. Chandana Priya, C., Seshagiri Rao, M.V., Srinivasa Reddy, V., Int. J. of Civil Eng. and Tech., 9(11), pp. 2218-2225 (2018)

22. M. Kavitha, P. B. Bobba and D. Prasad, 2016 7th India International Conference on Power Electronics (IICPE), 2016, pp. 1-6

23. Satya Sai Trimurty Naidu, K., Seshagiri Rao, M.V., Srinivasa Reddy, V., Int. J. of Civil Eng. 
and Tech., 9(11), pp. 2383-2393 (2018)

24. Supriya, Y., Srinivasa Reddy, V., Seshagiri Rao, M.V., Shrihari, S., Int. J. of Rec. Tech. and Engi., 8(3), pp. 5381-5385 (2019)

25. Kotkunde, N., Krishna, G., Shenoy, S.K., Gupta, A.K., Singh, S.K. International Journal of Material Forming, 10 (2), pp. 255-266 (2017)

26. Govardhan, D., Kumar, A.C.S., Murti, K.G.K., Madhusudhan Reddy, G. Materials and Design, 36, pp. 206-214. (2012)

27. Kumar, P., Singhal, A., Mehta, S., Mittal, A. Journal of Real-Time Image Processing, 11 (1), pp. 93-109. (2016)

28. Karthik Rao, R., Bobba, P.B., Suresh Kumar, T., Kosaraju, S. Materials Today: Proceedings, 26, pp. 3085-3089, 2019

29. Raghunadha Reddy, T., Vishnu Vardhan, B., Vijayapal Reddy, P. International Journal of Applied Engineering Research, 11 (5), pp. 30923102 (2016)

30. S. U.M. Rao,T.H. Rao, K. Satyanarayana, and B. Nagaraju, Materials Today: Proceedings, 5(2), 4958 (2018)

31. Hussaini, S.M., Krishna, G., Gupta, A.K., Singh, S.K. Journal of Manufacturing Processes, 18, pp. 151-158 (2015) 